
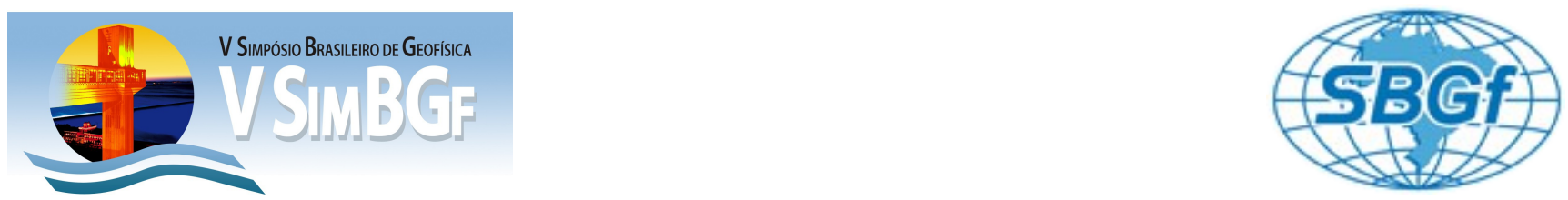

\title{
Espessura da crosta da porção leste da Província Borborema - norte do Cráton São Francisco: uma aproximação por função do receptor em estações sismográficas de período curto.
}

\author{
*Fábio Augusto S. Rocha ${ }^{1}$; Cassia Luisa Oliveira Peixotoํㅜ José Eduardo P. Soares ${ }^{1}$; Reinhardt A. Fuck ${ }^{1}$ \\ ${ }^{1}$ Laboratório de Estudos da Litosfera/IG/UnB (LabLitos)
}

Copyright 2012, SBGf - Sociedade Brasileira de Geofísica

Este texto foi preparado para a apresentação no V Simpósio Brasileiro de Geofísica, Salvador, 27 a 29 de novembro de 2012. Seu conteúdo foi revisado pelo Comitê Técnico do V SimBGf, mas não necessariamente representa a opinião da SBGf ou de seus associados. É proibida a reprodução total ou parcial deste material para propósitos comerciais sem prévia autorização da SBGf.

\section{Resumo}

The Borborema Province presents a large variety of lithologies, separated by faults and lineaments. Between February and March 2011 was carried out deep seismic refraction study in the region. Using the method of receiver function has been generated a model structure speed in the crust stations three components installed in the profile, and thus calculated and the depth of Moho ratio $\mathrm{Vp} / \mathrm{Vs}$. The final products obtained by the applied technique confirmed the results of deep seismic refraction getting values very close to the same $\mathrm{Vp}$ and $\mathrm{Vp} / \mathrm{Vs}$ obtained previously.

\section{Introdução}

A Província Borborema ou região de Dobramentos Nordeste é uma entidade tectônica que se apresenta na parte mais ocidental do território brasileiro e também está presente em uma extensão dentro do continente africano. Limitada a norte pelo Cráton São Luis, a sul pelo Cráton São Francisco e a oeste pela Bacia do Parnaíba. A Província Borborema é considerada um grande mosaico de cinturões dobrados metassedimentares e maciços separados por zonas de cisalhamento neoproterozoicas, contendo ainda expressivo magmatismo granitico ao longo de sua extensão. As características estruturais desta Província se desenvolveram principalmente ao final do Mesoproterozóico até o limite NeoproterozóicoCambriano (Orogenêse Brasiliana/ Pan-Africana).

A configuração resultante do encontro dos vários domínios foi: Externo ao sul da zona de cisalhamento Pernambuco, Transversal entre os Lineamentos Pernambuco e Paraíba (Patos), e Rio Grande do Norte, Ceará Central e Médio Coreaú (NW Ceará) com sua extensões sob os sedimentos da bacia do Parnaíba incluindo também o Domínio Tocantins que acredita-se pertence a Província Borborema. Na região setentrional da província observam-se os domínios Médio Coreaú, Ceará Central, Orós-Jaguaribe e Faixa Seridó, separados uns dos outros por importantes zonas de cisalhamento. A região central, ou Domínio da Zona Transversal, é delimitada pelos lineamentos Patos (Paraíba) e Pernambuco. Contém vários segmentos internos de direção NE-SW, deformados e rotacionados no sentido horário. Do litoral para o interior, são discriminados os terrenos Rio Capibaribe, constituído por associações supracrustais neoproterozóicas e mais antigas, intrudidas por granitos brasilianos; Alto Moxotó, com predominância de embasamento paleoproterozóico retrabalhado e poucas intrusões brasilianas. A zona transversal mostra um complexo arranjo de terrenos paleoproterozóicos, eventualmente com núcleos arqueanos, mesoproterozóicos e neoproterozóicos O domínio meridional é constituído pelo Maciço PernambucoAlagoas e as faixas Sergipana e Riacho do Pontal.

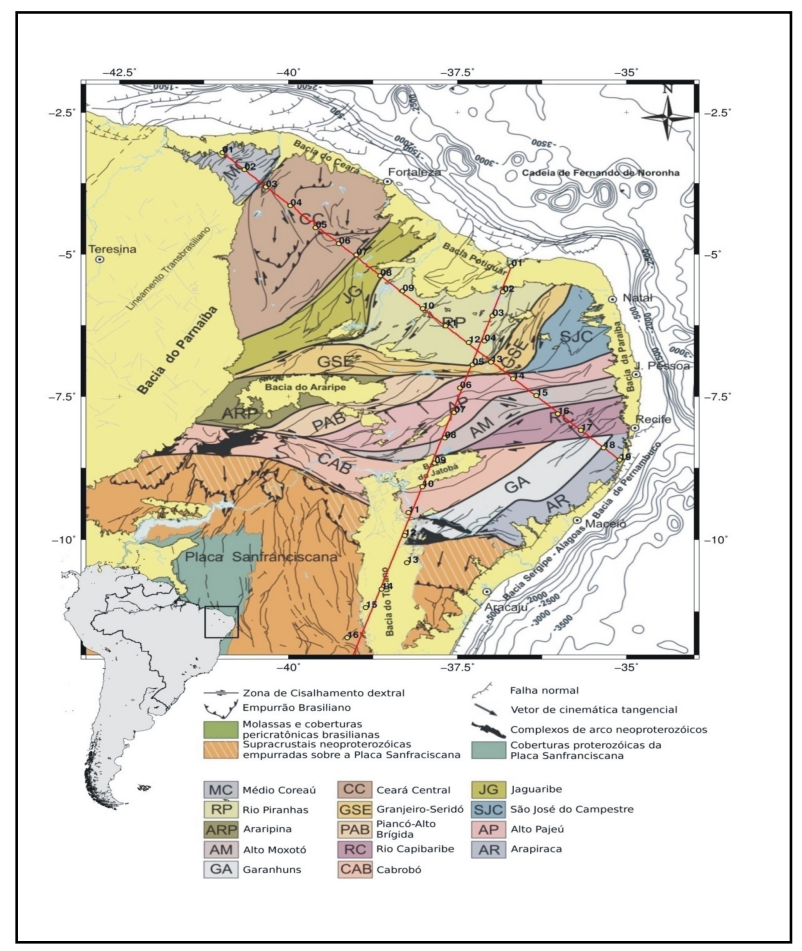

Figura 1 - Mapa Geológico Província Borborema. 


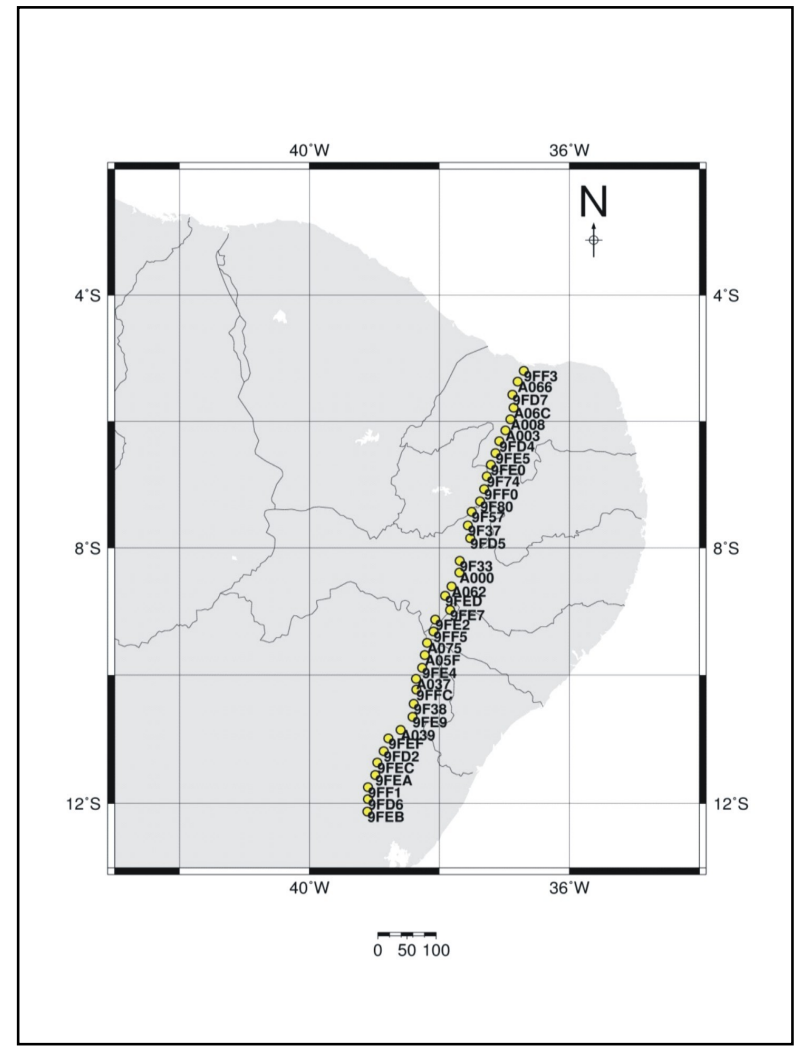

Figura 2 -Perfil Sísmico Província Borborema Estações 3 componentes

\section{Metodologia/ Problema Investigado}

A função do receptor é uma técnica geofísica que utiliza registros telessísmicos com epicentros distando entre $30^{\circ}$ e $90^{\circ}$ de uma estação sismográfica para inferir a estrutura de velocidade para a crosta sob uma estação sismológica de três componentes. Essa técnica é resumidamente a deconvolução da componente radial com a vertical (Langston, 1979; Owens et al, 1984; 1987; Ammon et al., Ammon, 1991). É usada para obter-se a razão de Poisson e a profundidade da descontinuidade crosta-manto (descontinuidade de Mohorovicic).

A FR obtém essas informações a partir do tempo de chegada da fase Ps e das múltiplas (PpPms, PpSms + PsPms) geradas a partir de parte da energia da $P$ incidente na descontinuidade da base da crosta sob a estação. As frentes de onda incidem próximas à vertical abaixo de uma estação, que registra a onda $P$. Essa fase é dominante na componente vertical do registro, e a onda convertida em S predominante na componente radial. As fases Ps e suas múltiplas são obtidas deconvolvendo a componente vertical de registro da componente radial e tangencial. Deconvolvendo a componente vertical da componente radial é possível isolar a estrutura da Terra sob a estação em forma de uma série temporal.

Por meio do tempo de chegada dessas fases, e com o valor da Vp média na crosta calculamos profundidade da descontinuidade e razão $\mathrm{Vp} / \mathrm{Vs}$ a partir das relações abaixo:

$$
H=\frac{V_{P}\left(t_{P_{S}}-t_{P}\right)}{\left(\sqrt{\frac{V_{P}^{2}}{V_{S}^{2}}-p^{2} V_{P}^{2}}-\sqrt{1-p^{2} V_{P}^{2}}\right)},
$$

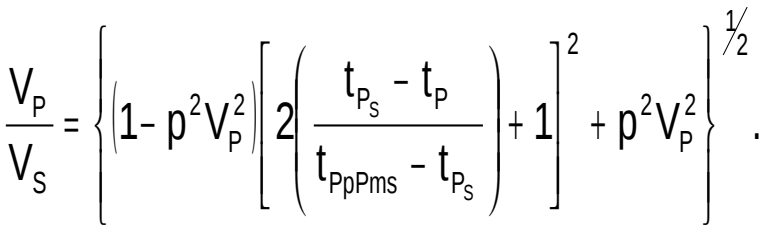

Onde $\mathrm{p}$ é o parâmetro de raio, $\mathrm{H}$ é espessura da crosta $\mathrm{e}$ t é o tempo de chegada das fases.

Com o valor da Vp obtido pelo método da sísmica de refração profunda para todos os dominios estudados foi possível tornar tempo da fase Ps em profundidade.

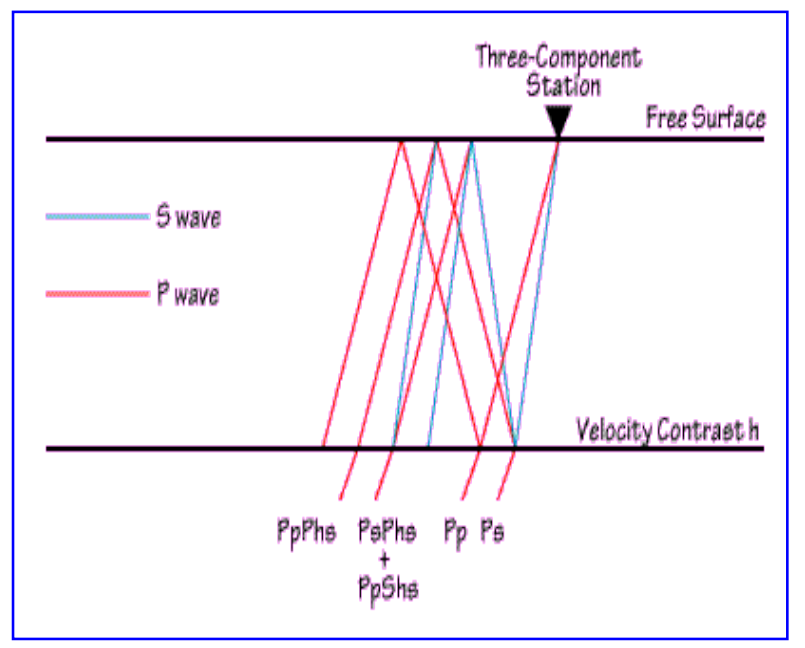

Figura 3 -Caminho das frentes de onda direta, refletidas e refratadas numa descontinuidade.

\section{Resultados}

O perfil sísmico foi divido de acordo com os domínios geológicos maiores identificados em superfície. Para obter a espessura da crosta sob o perfil sísmico NW-SE da Província Borborema, utilizamos a técnica de empilhamento dos traços sísmicos que possuíam valores de parâmetro de raio próximos. Para cada estação era gerado um único traço de função do receptor a partir da soma das componentes radiais, anteriormente, geradas para cada um dos eventos sísmicos. Assim, ao somar as 
componentes radiais nessa situação havia uma melhora da razão sinal-ruido no resultado obtido. $O$ procedimento citado é, agora, ilustrado na figura 4.

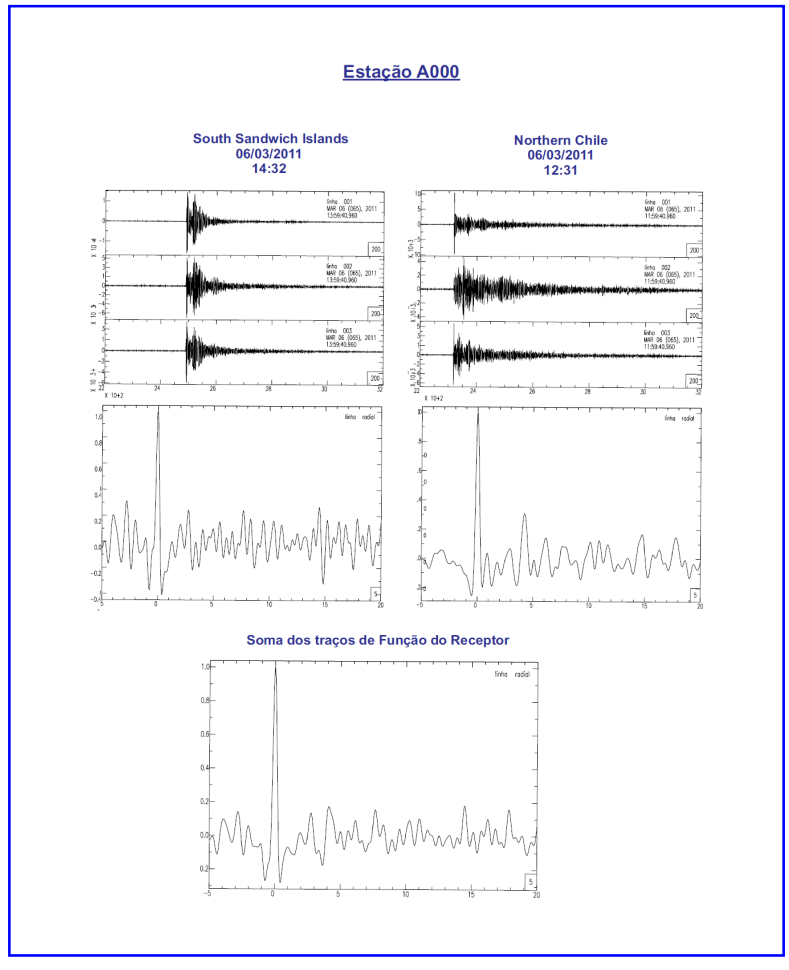

Figura 4 - Sismograma FR, após empilhamento.

Os resultados de $\mathrm{Vp} / \mathrm{Vs}$ e profundidade da crosta ao longo do perfil sísmico NW-SE da Província Borborema foram obitdos a partir da inversão dos dados no programa HK-Stacking. E, ainda, por meio do calculo direto com base na diferença das fases $\mathrm{P}$ e Ps e multiplas.

O domínio Rio Grande do Norte apresenta espessura média da crosta de $31 \mathrm{Km}$ com $\mathrm{Vp} / \mathrm{Vs}$ no valor de 1,74 $\mathrm{km} / \mathrm{s}$ e $\mathrm{Vp}$ de $6.45 \mathrm{~km} / \mathrm{s}$ e tempo da fase Ps variando entre 3,6 e $4,1 \mathrm{~s}$.

O domínio da Zona Transversal apresenta uma topografia da Moho mais movimentada tendo a maior dispersão entre os resultados obtidos. A espessura média encontrada foi de $35 \mathrm{~km}$ para $\mathrm{Vp} / \mathrm{Vs}$ de $1,70 \mathrm{~km} / \mathrm{s}$, $V p$ de $6,5 \mathrm{~km} / \mathrm{s}$ e tempo de fase Ps entre 3,7 e 4,6 s.

O domínio da Faixa Sergipana apresenta espessura média de $36 \mathrm{~km}, \mathrm{Vp} / \mathrm{Vs}$ de $1,70 \mathrm{~km} / \mathrm{s}, \mathrm{Vp}$ igual a $6,1 \mathrm{~km} / \mathrm{s}$ e tempo de fase Ps variando de 4,2 a 4,5 s.

O Cráton do São Francisco, mais precisamente Bloco Serrinha, apresenta Ps igual a 4,6 s para $V p / V s$ de 1,70 $\mathrm{km} / \mathrm{s}, \mathrm{Vp}$ de $6,1 \mathrm{~km} / \mathrm{s}$ e espessura da crosta em $38 \mathrm{~km}$.

As estações situadas nas bacias Potiguar, Jatobá e Tucano não apresentaram resultados para a técnica aplicada apesar de possuirem os registros dos eventos em seus bancos de dados. Supõe-se que isso ocorreu devido a alta carga sedimentar existente nestas bacias.
Esse estudo com a técnica Função do Receptor confirma o modelo de espessura crustal obtido anteriormente por refração sísmica profunda como .

\section{Domínio Rio Grande do Norte}

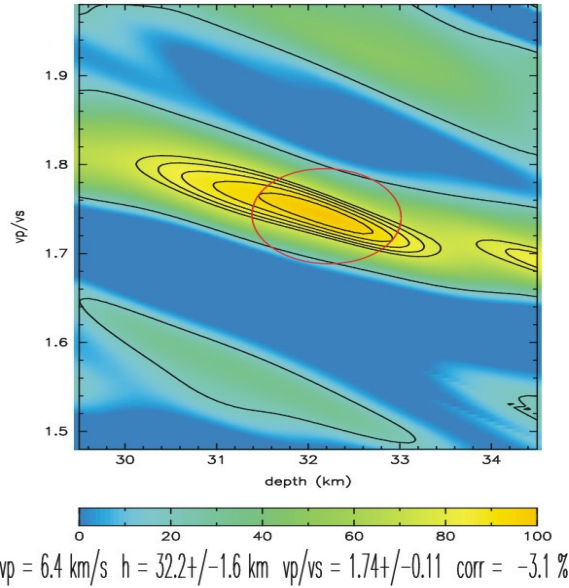

Domínio Zona Transversal

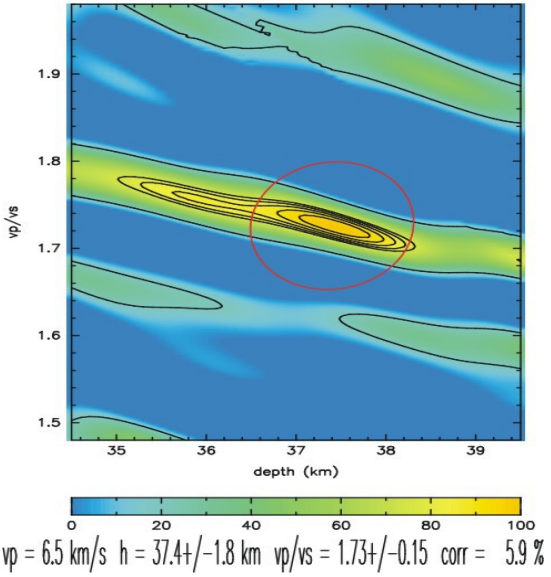

Domínio Pernambuco - Alagoas

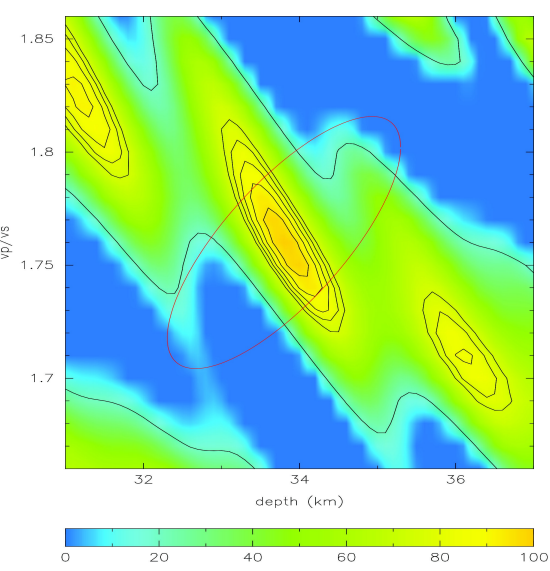

$v_{p}=6.4 \mathrm{~km} / \mathrm{s} h=33.8+f-3.0 \mathrm{~km}$ vp/ $/ \mathrm{ss}=1.76 t /-.11$ corr $=75.7 \%$ 


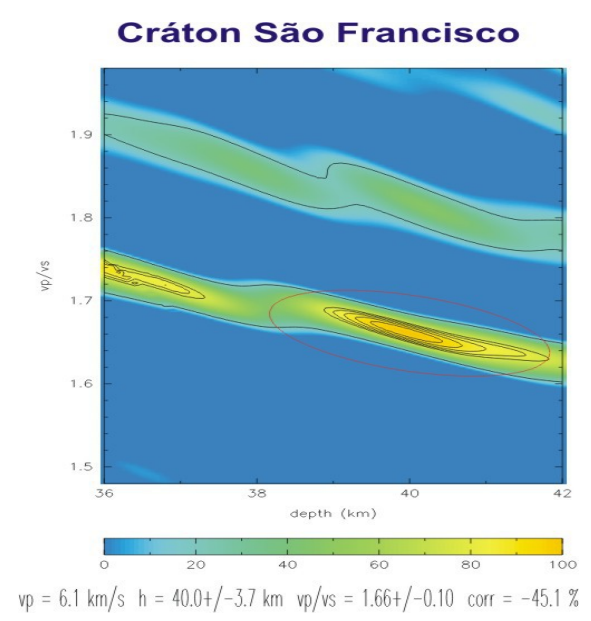

Figura 5 - Resultados obtidos pelo programa HkStacking.

\section{Discussão e Conclusões}

Verificou-se que existe um espessamento da crosta na direção norte-sul do perfil sísmico. Sendo mais profunda no Cráton São Francisco e mais rasa no domínio Rio Grande do Norte.

Nas regiões de bacia sedimentar não foi possível obter resposta de função do receptor apesar de se observar o registro dos eventos sísmicos nas estações tri-axiais. Acredita-se que isso ocorre devido a alta reflexão que a onda sofre ao incidir na descontinuidade entre embasamento e bacia sedimentar.

Em geral, onde se encontrou um limite de crosta mais profundo percebia-se em superfície uma elevação da topografia.

A análise das espessuras crustais da região, considerando $\mathrm{Vp}$ e $\mathrm{Vp} / \mathrm{Vs}$ enfatizam as diferenças estruturais entre os domínios presentes na província Borborema.

Embora subproduto do levantamento sísmico, os resultados de função do receptor são um vínculo importante para o calculo da profundidade da Moho. E a técnica revela-se uma ferramenta de extrema utilidade ao estudo de refração sísmica profunda, pois, nas extremidades do perfil sísmico, onde não existe cobertura de raios refratados, a função do receptor apresenta resultados consistentes.

De forma geral a topografia da Moho é bastante movimento sob o perfil, com variação de espessura da crosta de cerca de $8 \mathrm{~km}$, evidenciando a complexidade estrutural e longa história crustal que envolve a província.

\section{Agradecimentos}

Ao Laboratório de Estudos da Litosfera- UnB por ter cedido os dados e materiais para o desenvolvimento dessa pesquisa. Ao professor Dr. José Eduardo Pereira Soares por ter orientado e incentivado os estudos sobre estrutura crustal. A Jônatas de Sales M. Carneiro por ter cedido seus dados de velocidade da $\mathrm{Vp}$ e $\mathrm{Vp} / \mathrm{Vs}$ e seu modelo de espessamento da crosta obtidos por refração sísmica profunda.

\section{Referências}

Zandt G. \& Ammon C.J. 1995. Continental crust composition constrained by measurements of crustal Poisson's ratio. Nature, 374:152-154.

Zandt G., Myers S.C., Wallace T.C. 1995. Crust and mantle structure across the Basin and Range-Colorado Plateau boundary at $37^{\circ} \mathrm{N}$ latitude and implications for Cenozoic extensional mechanism. Journal of Geophysical Research, 100 :10529-10548.

Barros L. V., Assumpção M., 2011. Basement depths in the Parecis Basins with receiver functions form small local earthquakes in the Porto dos Gaúchos seismic zone. Journal of South American Earth Sciences 32. 142 - 151

Ventura, D. B. R., 2011. Caracterização sísmica e gravimétrica da litosfera soba linha de refração sísmica profunda de Porangatu, Província Tocantins, Brasil Central. Revista Brasileira de Geociências. 130 - 140.

Dugda, M. T., Nyblade ,A. A., Ammon C. J. 2005. Crustal structure in Ethiopia and Keniafrom receiver function analysis: Implications for rift development in eastern Africa. Journal of Geophysical Research, vol 110, B01303, doi:10.1029/2004JB003065.

Almeida, F. F. M., Hasui, Y., Brito Neves, B.B., Fuck, R.A. 1977. Províncias Estruturais Brasileiras. In: SBG/Núcleo Nordeste, 8 Simp. Geol. Nordeste, Campina Grande (PB ), Boletim, 6: $363-391$.

Mabessone, J. M. 2002. História Geológica da Província Borborema (NE Brasil). Revista de Geologia. Vol 15: 119 $-129$.

Ammon, C.J., 1997. An overview of receiver function analysis. Citação de referências e documentos eletrônicos. Disponível em: http://www.essc.psu.edu/ ammom/ HTML/RftnDocs/rftn01.html.

Zhu, L., Kanamori, H. 2000. Moho Depth variation in southern California from teleseismic receiver functions. Journal of Geophysical Research, Vol. 105, 2969-2980.

Schobbenhaus, C., Campos, D. A. 1984. Geologia do Brasil. 131-195. 


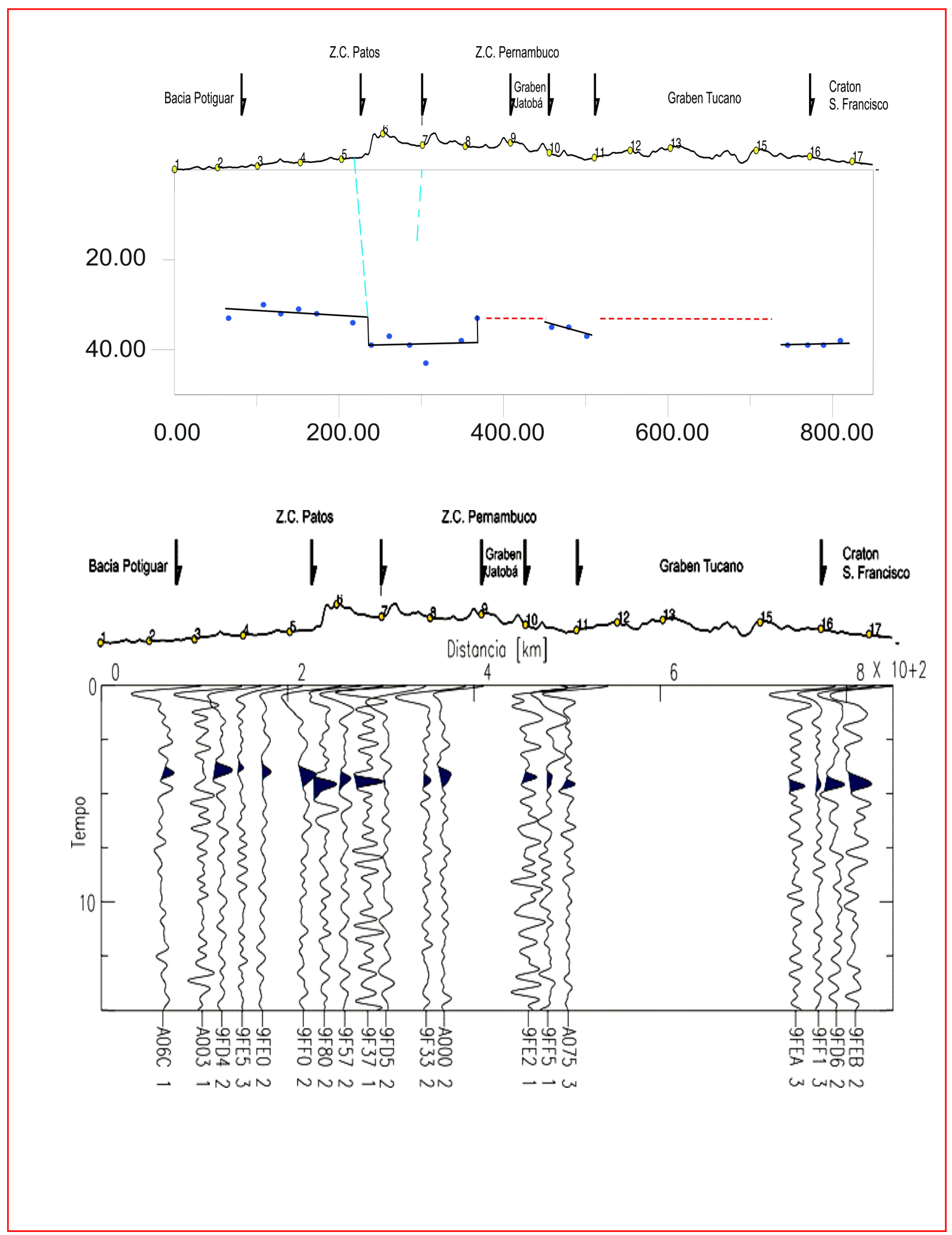

Figura 6 - Modelo de Espessura Crustal e Sismograma Final de Função do Receptor da Província Borborema. 